\title{
Anaplastic Large Cell Lymphoma, Lymphomatoid Papulosis-Like Histology
}

National Cancer Institute

\section{Source}

National Cancer Institute. Anaplastic Large Cell Lymphoma, Lymphomatoid Papulosis-

Like Histology. NCI Thesaurus. Code C7200.

An anaplastic large cell lymphoma characterized by the presence of histopathologic

features reminiscent of lymphomatoid papulosis. These features include the presence of Hodgkin-like cells in a background of acute and chronic inflammation. 